\title{
Editorial
}

\section{"Novel Approaches in Landslide Monitoring and Data Analysis" Special Issue: Trends and Challenges}

\author{
Jan Blahůt ${ }^{1, *}$, Michel Jaboyedoff ${ }^{2} \mathbb{D}$ and Benni Thiebes ${ }^{3}(\mathbb{D}$ \\ 1 Institute of Rock Structure and Mechanics, The Czech Academy of Sciences, V Holešovičkách 94/41, \\ 18200 Prague, Czech Republic \\ 2 Risk Analysis Group, Institute of Earth Sciences, University of Lausanne, 1015 Lausanne, Switzerland; \\ michel.jaboyedoff@unil.ch \\ 3 German Committee for Disaster Reduction (DKKV), Kaiser-Friedrich-Str. 13, 53113 Bonn, Germany; \\ benni.thiebes@dkkv.org \\ * Correspondence: blahut@irsm.cas.cz; Tel.: +420-266-009-394
}

check for

updates

Citation: Blahůt, J.; Jaboyedoff, M.; Thiebes, B. “Novel Approaches in Landslide Monitoring and Data Analysis" Special Issue: Trends and Challenges. Appl. Sci. 2021, 11, 10453. https://doi.org/10.3390/ app112110453

Received: 3 November 2021 Accepted: 4 November 2021 Published: 7 November 2021

Publisher's Note: MDPI stays neutral with regard to jurisdictional claims in published maps and institutional affiliations.

Copyright: (c) 2021 by the authors. Licensee MDPI, Basel, Switzerland. This article is an open access article distributed under the terms and conditions of the Creative Commons Attribution (CC BY) license (https:// creativecommons.org/licenses/by/ $4.0 /)$.
Keywords: landslide; monitoring; modelling; susceptibility; InSAR

\section{Introduction}

The purpose of this Special Issue is to bring together recent studies related in particular to landslide monitoring and data analysis. In engineering geology, geotechnical engineering and geomorphology, landslide monitoring using standard techniques is quite common. However, the rapid development of both hardware and software solutions, including miniaturization or remote sensing techniques, brings new possibilities for increasing monitoring accuracy, real-time or near-real-time data analysis and early warning.

\section{Summary of the Special Issue Contents}

The Special Issue topics can be sub-divided into three groups according to the main topic covered by the articles. The majority of the articles (seven) are focused on landslide monitoring, monitoring data analysis and surveying, while a further two papers are focused on slope stability modelling using large-scale analog models and the remaining four papers deal with landslide susceptibility and detection.

\subsection{Landslide Monitoring, Monitoring Data Analysis and Surveying}

Thiery et al. [1] performed airborne electromagnetic measurements for rapid surveyance of the volcanic tropical environment of La Martinique, an island in the Caribbean. They combined their findings with a physical-based model to obtain improved and integrated information about the internal structure of landslides, founding a better understanding of landslides' initiation conditions.

Gili et al. [2] have monitored the Vallcebre landslide in the Pyrenees in NE Spain since 1987. A range of classical and novel methods have been used to that end (e.g., triangulation, photogrammetry, wire extensometers, GNSS-GPS, satellite DInSAR and terrestrial GBSAR). They conclude that while some methods give higher-precision results than others, all systems play valuable roles in landslide movement interpretation, and provide meaningful monitoring results at different study stages.

Fang et al. [3] present a monitoring system installed on the Pingding landslide in Taiwan. Their system consists of a GPS array combined with inclinometers, extensometers and rainfall data. The system is emergency response-centered and provides a basis for local early-warning indices. The paper tackles the important issue of multilateral cooperation among different subjects and disciplines involved in landslide disaster management.

Qiao et al. [4] focus on early-warning methods for largely abandoned rockfill slopes. These pose a significant threat in areas of large construction works. The authors used 
ground-based InSAR to monitor slope deformations and verified the method on five landslides in the area of Huangdao, China.

Dabiri et al. [5] used object-based image analysis to map geomorphological features, and assessed the applicability of Sentinel-1 data to the fast creation of post-landslide digital elevation models. Their findings revealed that-without further post-processing-the automatically derived results need to be interpreted with care, as the automatic generation of a digital elevation model is influenced by several factors.

Blahưt et al. [6] propose a methodology for analyzing time-series monitoring data from a large, slow-moving San Andrés landslide on El Hierro, Canaries, Spain. They used precise 3D dilatometric data and compared them with possible landslide-triggering factors (e.g., seismic, rainfall) to allow for fully automatic processing, thus decreasing the subjectivity of the analysis.

Troiani et al. [7] applied different surface analysis and monitoring methods to decipher the structural controls of rock slope stability in coastal areas. They worked on the Adriatic coast of the Conero promontory in Central Italy, and their results stress the need to analyze slope stability over a long timescale, to understand the current processes.

\subsection{Slope Stability Modelling Using Large-Scale Analog Models}

Feng et al. [8] determined a soil-water characteristic curve for landslide seepage under varying hydrodynamic conditions. They used large-scale experiments combined with finite element modelling. Consequently, they evaluated the uncertainties in the modelling using the Bayesian approach.

Tang et al. [9] assessed the influence of an intermediate coarse layer on slope stability during heavy rainfall. They found that the unsaturated hydraulic conductivity in the coarse layer was much lower than that of a fine layer, which led the capillary barrier to work at a lower water content. They also revealed that the coarser layers may have negative effects on slope stability.

\subsection{Landslide Susceptibility and Detection}

Fabbri and Patera [10] searched for uncertainties associated with the prediction patterns of landslide susceptibility maps. They conclude that the properties of prediction patterns are mostly unknown, but nevertheless, are critical for interpreting and justifying prediction results.

Lai [11] performed an automated data-mining procedure to differentiate the landslide sources and runout zones of landslides triggered by Typhoon Morakot in Taiwan. The author's models revealed that the detection of landslide sources provided accurate results, while the extraction of the runout areas achieved excellent accuracies.

Li et al. [12] explored the influence of multitemporal digital elevation models on the generation of susceptibility maps in the southern Sichuan Province in China. They conclude that the susceptibility assessment level of an area with historical landslides decreases in the short-term and that the usage of multitemporal digital elevation models has a serious impact on susceptibility results.

Li et al. [13] prepared a spatial, proximity-based, geographically weighted regression susceptibility model for the Qingchuan area in China. Their results suggest that the newly developed model shows higher predictive accuracy than five other commonly used models.

\section{Bibliometric Analysis of Current Trends}

A simple bibliometric analysis was performed in the ISI Web of Knowledge: "Web of Science Core Collection" (1900-Present) to capture the main trends in the Special Issuerelated topics. The statistics were gathered on 2 November 2021, so only the first ten months of the year 2021 were included in the search. We followed a similar approach to Jaboyedoff et al. [14] and selected keywords related to the topic of this Special Issue. A number of papers published in every year have been analyzed for the query "TOPIC" (Table 1). 
Table 1. List of queries used in simple bibliometric analysis. Timespan: 1900-Present. Indices: SCI-EXPANDED, SSCI, A\&HCI, CPCI-S, CPCI-SSH, BKCI-S, BKCI-SSH, ESCI, CCR-EXPANDED, IC.

\begin{tabular}{|c|c|}
\hline Keyword & $\begin{array}{l}\text { ISI Web of Science Core Collection (1900-Present) Query for } \\
\text { "TOPIC" }\end{array}$ \\
\hline Landslide & (landslide ${ }^{*}$ OR rockslide * OR rockfall * OR rock-fall *) \\
\hline Monitoring & $\begin{array}{c}\text { (monitoring * OR surveying *) AND (landslide * OR rockslide * } \\
\text { OR rockfall }{ }^{*} \text { OR rock-fall }{ }^{*} \text { ) }\end{array}$ \\
\hline Susceptibility or modelling & $\begin{array}{l}\text { (susceptibility } * \text { OR modelling } * \text { OR modeling } * \text { OR assessment } \\
\text { *) } \\
\left.\text { AND (landslide } * \text { OR rockslide }{ }^{*} \text { OR rockfall }{ }^{*} \text { OR rock-fall }{ }^{*}\right)\end{array}$ \\
\hline InSAR & $\begin{array}{l}(\text { InSAR } * \text { OR DInSAR * OR GBSAR * OR GB-InSAR *) AND } \\
(\text { landslide * OR rockslide * OR rockfall * OR rock-fall *) }\end{array}$ \\
\hline
\end{tabular}

*: Search keywords.

Before 1990, only a small share of the total number of papers had been published. For the topic "landslides", only 585 papers (1.65\%) were published before 1990 out of 35,440 (till 10/2021); for the "landslide + monitoring" topic, only nine papers $(0.17 \%)$ were published before 1990 out of 5210 (till 10/2021); and for the topic "landslide + susceptibility, modelling or assessment", only 13 papers $(0.11 \%)$ were published before 1990 out of 12,248 (till 10/2021). In the case of the "landslide + InSAR" topic, the first publication appeared in 1998, and up to the end of October this year, 1079 papers had been published. Figure 1 shows the yearly growth in the number of papers in the respective topics since 1990. The presented graphs illustrate the fast-growing exponential trend in all the analyzed topics. However, the fastest growth in recent years can be seen in the "landslide + InSAR" topic.

One of the basic variables for assessing the trends in a time-series is the growth rate [15]:

$$
k_{i}=\frac{y_{i}-y_{i-1}}{y_{i-1}} \cdot 100
$$

where $k_{i}$ is the growth rate in $\%, y_{i}$ is the value at the time $i$ and $y_{i-1}$ is the value at time $i-1$.

Positive values mean a growth in percentage terms compared to the previous year while negative values mean a decrease compared to the previous year in percentage terms. As can be seen from Figure 2, rapid growth in topics "landslides", "monitoring" and "susceptibility" in the 1990s has stabilized since 2006; studies on these topics are now increasing at a relatively stable rate of around $10-15 \%$ per year. The "InSAR" topic is a special case as the first paper appeared in 1998, which consequently resulted in very high growth rates. However, during the last five years, this trend seems to have stabilized, and the topic now seems to follow the trend of the other three topics with a yearly growth rate of between 15 and $20 \%$. 

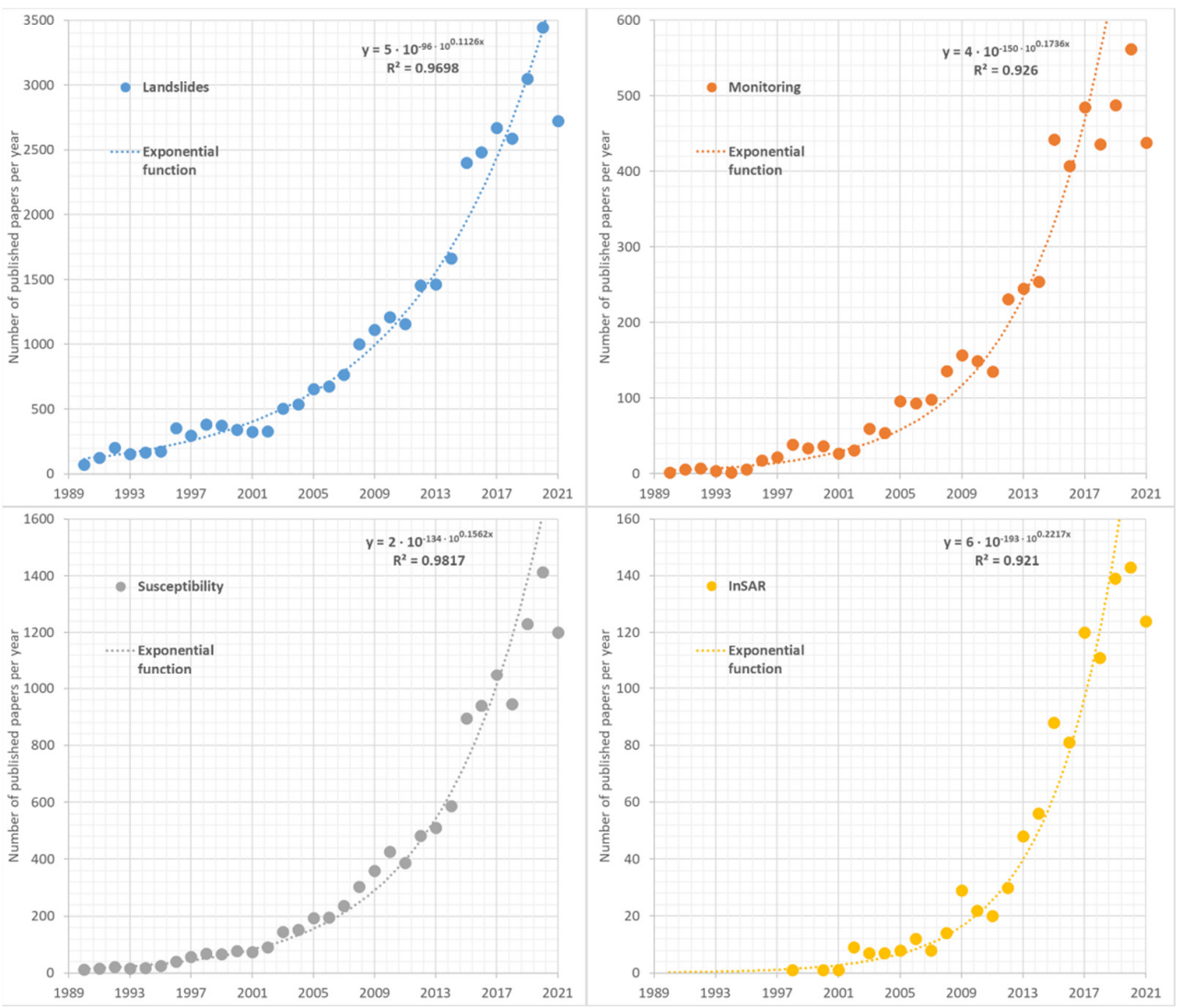

Figure 1. Number of published papers per year on the selected topics since 1990.

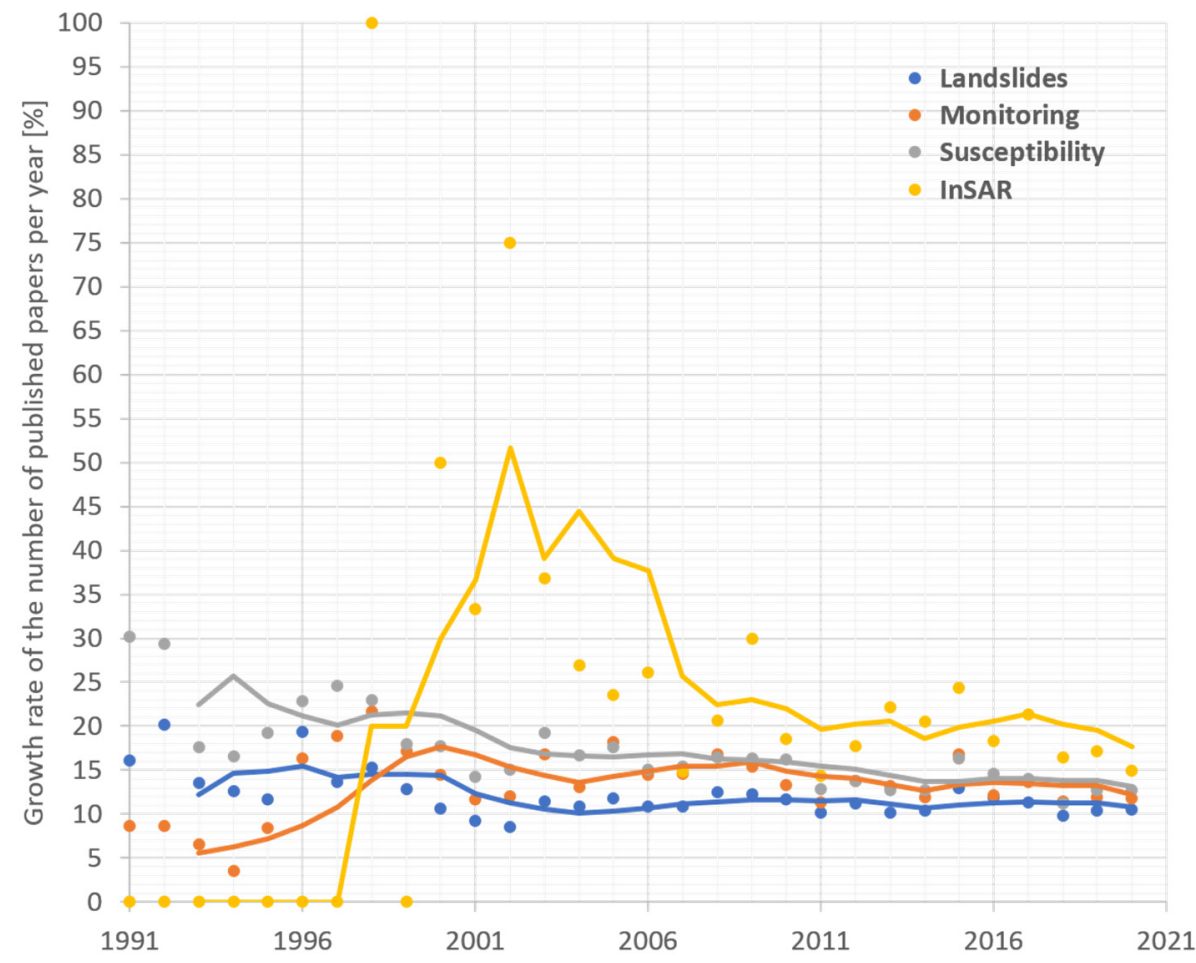

Figure 2. Growth rate of the number of published papers per year on the selected topics since 1990. Lines show the five-year moving average. 


\section{Future Challenges}

Future trends are always hard to predict. It can be expected, however, that the current trend of yearly growth in the number of papers published on the Special Issue topics, of between $110 \%$ and $120 \%$, will continue during the next five to ten years. This could result in more than 10,000 papers published per year on the "landslides" topic by 2026, or 20,000 papers published by 2030. It is questionable whether this enormous number of papers could be published as to do so would place enormous pressure on all the persons involved in the publication process, especially the editors and reviewers. Even now, it is hard to ensure a rigorous peer-review process as scientists are often overloaded with review requests. This situation is unsustainable in the long-term and indicates that we might expect important changes in the publication process of landslide-related scientific papers.

One possible step toward solving this situation is to better classify the type of paper published. Papers should be distinguished between novel, innovative papers and applications of existing techniques and methodologies (case studies). While the innovative papers are potentially highly citable, the case studies bring new examples. Thus, both types are important, but do nothing to decrease the overload faced by editors and reviewers.

Author Contributions: J.B. prepared the manuscript, M.J. and B.T. revised and edited the text. J.B., M.J. and B.T. were Guest Editors of this Special Issue and, therefore, reviewed all the submissions. All authors have read and agreed to the published version of the manuscript.

Funding: This research received no external funding.

Data Availability Statement: The data analyzed in this paper have been downloaded from "Web of Knowledge Core Collection" (https:/ / www.webofscience.com/wos/woscc/advanced-search, on 2 November 2021).

Acknowledgments: The Guest Editors would like to acknowledge the external reviewers that assured the quality standards of the Applied Sciences journal were reached through their much-appreciated iterative review process. The authors, assistant editors and academic editors are also gratefully acknowledged for their interest in contributing to this Special Issue.

Conflicts of Interest: The authors declare no conflict of interest. The funders had no role in the design of the study; in the collection, analyses or interpretation of data; in the writing of the manuscript or in the decision to publish the results.

\section{References}

1. Thiery, Y.; Reninger, P.-A.; Nachbaur, A. Airborne Electromagnetics to Improve Landslide Knowledge in Tropical Volcanic Environments. Appl. Sci. 2021, 11, 3390. [CrossRef]

2. Gili, J.A.; Moya, J.; Corominas, J.; Crosetto, M.; Monserrat, O. Past, Present and Future Monitoring at the Vallcebre Landslide (Eastern Pyrenees, Spain). Appl. Sci. 2021, 11, 571. [CrossRef]

3. Fang, Y.M.; Chou, T.Y.; Hoang, T.V.; Bui, Q.T.; Nguyen, D.B.; Nguyen, Q.H. New Landslide Disaster Monitoring System: Case Study of Pingding Village. Appl. Sci. 2020, 10, 6718. [CrossRef]

4. Qiao, N.; Duan, Y.-L.; Shi, X.-M.; Wei, X.-F.; Feng, J.-M. Study on the Early Warning Methods of Dynamic Landslides of Large Abandoned Rockfill Slopes. Appl. Sci. 2020, 10, 6097. [CrossRef]

5. Dabiri, Z.; Hölbling, D.; Abad, L.; Helgason, J.K.; Sæmundsson, P.; Tiede, D. Assessment of Landslide-Induced Geomorphological Changes in Hítardalur Valley, Iceland, Using Sentinel-1 and Sentinel-2 Data. Appl. Sci. 2020, 10, 5848. [CrossRef]

6. Blahůt, J.; Balek, J.; Eliaš, M.; Meletlidis, S. 3D Dilatometer Time-Series Analysis for a Better Understanding of the Dynamics of a Giant Slow-Moving Landslide. Appl. Sci. 2020, 10, 5469. [CrossRef]

7. Troiani, F.; Martino, S.; Marmoni, G.M.; Menichetti, M.; Torre, D.; Iacobucci, G.; Piacentini, D. Integrated Field Surveying and Land Surface Quantitative Analysis to Assess Landslide Proneness in the Conero Promontory Rocky Coast (Italy). Appl. Sci. 2020, 10, 4793. [CrossRef]

8. $\quad$ Feng, C.; Tian, B.; Lu, X.; Beer, M.; Broggi, M.; Bi, S.; Xiong, B.; He, T. Bayesian Updating of Soil-Water Character Curve Parameters Based on the Monitor Data of a Large-Scale Landslide Model Experiment. Appl. Sci. 2020, 10, 5526. [CrossRef]

9. Tang, J.; Taro, U.; Huang, D.; Xie, J.; Tao, S. Physical Model Experiments on Water Infiltration and Failure Modes in Multi-Layered Slopes under Heavy Rainfall. Appl. Sci. 2020, 10, 3458. [CrossRef]

10. Fabbri, A.G.; Patera, A. Spatial Uncertainty of Target Patterns Generated by Different Prediction Models of Landslide Susceptibility. Appl. Sci. 2021, 11, 3341. [CrossRef] 
11. Lai, J.-S. Separating Landslide Source and Runout Signatures with Topographic Attributes and Data Mining to Increase the Quality of Landslide Inventory. Appl. Sci. 2020, 10, 6652. [CrossRef]

12. Li, J.; Wang, W.; Han, Z.; Li, Y.; Chen, G. Exploring the Impact of Multitemporal DEM Data on the Susceptibility Mapping of Landslides. Appl. Sci. 2020, 10, 2518. [CrossRef]

13. Li, Y.; Liu, X.; Han, Z.; Dou, J. Spatial Proximity-Based Geographically Weighted Regression Model for Landslide Susceptibility Assessment: A Case Study of Qingchuan Area, China. Appl. Sci. 2020, 10, 1107. [CrossRef]

14. Jaboyedoff, M.; Del Gaudio, V.; Derron, M.-H.; Grandjean, G.; Jongmans, D. Characterizing and monitoring landslide processes using remote sensing and geophysics. Eng. Geol. 2019, 259, 105167. [CrossRef]

15. Definition of "Growth Rate" on the Webpage of The National Institute of Statistics and Economic Studies. Available online: https:/ / www.insee.fr/en/metadonnees/definition/c1362 (accessed on 2 November 2021). 